\title{
El mundo como vestigio de Dios Uno y Trino, según san Agustín.
}

\author{
"Ecce apparet mihi in aenigmate Trinitas, quod \\ es, Deus meus".
}

(Conf. XXIII, 5, PL 32,847).

\section{Introducción}

Según indica el mismo título, intentamos en este trabajo ofrecer una visión sintética del mundo como "vestigio de Dios", o de los vestigios trinitarios en el mundo, según la doctrina de San Agustín ${ }^{1}$.

1. La bibliografía genérica acerca de la semejanza e imagen de Dios en la doctrina de San Agustín es muy amplia y sigue aumentando constantemente. Aunque no se trata el tema en el mismo sentido que lo enfocamos en el presente artículo, pueden consultarse: M. Schmaus, Die psychologische Trinitätslehre des hl. Augustinus (Münster 1927); Ch. BOYER, "L'image de la Trinité, syntése de la pensée augustinienne": Gregorianum 27 (1946) 173-199, 333-352, etc.; R. A. MaRKus, "Imago" and "similitudo" in Augustine": Revue des Etudes Augustiniennes 10 (1964) 125143; L. Cillerueio, "Historia de la imagen de Dios": Archivo Teológico Agustiniano 1 (1966) 3-37; ID., "Quien es Dios? Semejanza e imagen": Estudio Agustiniano 8 (1973) 401-448; C. KALIBA, Dié Welt als Gleichnis des dreieinigen Gottes. Entwurf zu einer trinitarischen Ontologie (Salzburg 1954?); R. BERLINGEN, Augustins dialogische Metaphysik (Frankfurt am M. 1962); A. ScHINDLER, Wort und Analogie in Augustins Trinitätslehre (Tübingen 1965); A. TURRADo, "Nuestra imagen y semejanza divina. En torno a la evolución de esta doctrina en San Agustín": La Ciudad de Dios (Homenaje al P. A. C. Vega) 181 (1968) 776-801; ID., Dios en el hombre. Plenitud o tragedia (Madrid 1971). (En este bello libro se contienen interesantes sugerencias y abundante bibliografía); R. FLoREz, Las dos dimensiones del hombre agustiniano (Madrid 1958); ID., Presencia de la verdad. De la experiencia a la doctrina en el pensamiento agustiniano (Madrid 1971); M. F. ScIACCA, Ontologia triadica e trinitaria. Discorso metafísico-teologico (Milano 1972); E. MÜr.r.ER, Augustins Lehre von Einheit und Dreieinheit in ihrer Bedeutung für Sein und Erkennen (Erlangen 1929); H. E. HENGSTENBERG, Das Band zwischen Gott und Schöpfung (Regensburg 1948). Hemos tenido muy en cuenta estos dos últimos libros, a los que seguimos en algunos puntos, como se indicará oportunamente. Otros trabajos de que nos hemos servido se irán también citando a su debido tiempo. La primera vez presentaré siempre el título completo, $y$ después de forma abreviada). 
No vamos a estudiar aquí el tema de Dios en sí mismo, ni tampoco las características del mundo, sino la relación entre el Creador y la criatura en cuanto ésta constituye la primera semejanza o revelación de Dios.

Teniendo en cuenta que Agustín supera el escepticismo y que no admite el ontologismo, el punto de partida obligado para nuestro estudio tiene que ser el mismo mundo 2. Pero no para "demostrar" la existencia de Dios en virtud de determinados principios metafísicos, sino para encontrar las huellas del Creador y rastrear de algún modo los rasgos de su figura. En realidad, Agustín rara vez intenta demostrar con riguroso silogismo la existencia de Dios, salvo algunos ensayos en obras de primera época ${ }^{3}$. La existencia de Dios la da por supuesta desde la fe y desde el momento en que él mismo ha creído experimentarlo en su vida. El ateísmo es para Agustín una auténtica "locura de pocos" ${ }^{4}$. El observa más bien las cosas creadas en cuanto son un reclamo hacia Dios, y en cuanto le permiten adquirir un concepto más rico y preciso del Creador. A la vez, el enfoque divino de las cosas le ayuda para una mayor comprensión de sí mismo y del mundo.

El filósofo y el hombre religioso se han preocupado siempre de contemplar el mundo desde una altura superior para descubrir el oculto y más profundo sentido de las cosas, en relación con Dios. Agustín asimila la tradición bíblica y filosófica, si bien todas las influencias que él recibe las transfigura y elabora originalmente en el crisol de su fuerte personalidad y experiencia. Desde los primeros tiempos de su carrera literaria se nota el afán de descubrir a Dios en la realidad mundana, aunque siempre lo hace en plan de ensayo o sugerencia, con cautela y temblor. El maniqueísmo y el platonis-

2. Cuando hablamos del mundo nos referimos al mundo material, en el que se dan los "vestigios trinitarios", y prescindimos del mundo espiritual del hombre, en el que se halla la "imagen de Dios" (conf. $\mathrm{X}, 6$, 9-10: PL 32, 783).

3. De Lib. arb. II, 3, 7-15, 20: PL 32, 1243-1263; De Vera rel. cap. 2931: PL 34, 145-148.

4. "Pauci inveniuntur tantae impietatis, ut impleatur in eis quod scriptum est: Dixit stultus in corde suo, Non est Deus (Psal. 13,1). Insania ista paucorum est. Sicut magna pietas, paucorum est; ita et magna impietas, nihilominus paucorum est" (Ser. 119, 2, 3: PL 38,441). "Difficile est ut incurramus in hominem qui dicat in corde suo, Non est Deus" (In PS. 102, 2: PL 36, 613). Cf. R. FloRez, Presencia de la verdad. De la experiencia a la doctrina en el pensamiento agustiniano (Madrid 1971) 203250 . 
mo le habian preparado para una visión metafísica y trascendente del mundo. La lectura de la Biblia, la palabra de Ambrosio y su propio temperamento de poeta, de filósofo y de místico completan esta visión simbólica y profunda de la realidad.

Dios se hace visible a través de la unidad, de la belleza, del orden admirable que reina por doquier, es decir a través de los múltiples valores impresos en todos los seres, según su gradación. Estos valores objetivos son patentes a todos los ojos humanos, pero no todos saben juzgarlos adecuadamente, porque no todos confieren la voz o signo recibidos de fuera con la voz interior que habla en el corazón ${ }^{5}$. Frente a esos valores de las cosas, relativos y mudables, Agustín se pregunta: ¿De dónde proceden? ¿Qué sentido tienen? ¿Cuál es su misión y su mensaje? $Y$ su respuesta es siempre invariable: todos los bienes o valores creados son "vestigios del Creador", todas las cosas cantan al Hacedor y nos revelan algo de El. Y como Dios es Uno y Trino, nos encontramos en la obra del Supremo artista con los vestigios de la unidad y de la trinidad. Agustín investiga y fundamenta lo que podríamos llamar una "metafísica trinitaria de los seres creados" y se afana por encontrar multiplicidad de tríadas. En los libros científicos (Tratado de la Santísima Trinidad, La Ciudad de Dios, Comentarios al Génesis...) se ha dedicado a investigarlas y enumerarlas; en las obras populares (Sermones, Comentarios a los Salmos...) emplea un lenguaje de acentos líricos para cantar las múltiples maravillas que le hablan de Dios.

\section{El método agustiniano}

Dos aspectos principales nos interesa señalar aquí. El primero, que Agustín no hace uso "puro" de la razón, sino que acude simultáneamente a los datos de la revelación. Los planos de la fe y de la filosofía, aunque sean distintos teóricamente, en la práctica se encuentran siempre unidos. La razón y la fe son los dos caminos inseparables para Agustín: "fides quaerens intellectum" e "intellectus quaerens fidem". En lo que aquí concretamente nos interesa, es evidente que los "vestigia Trinitatis" tienen sentido sólo para los creyentes y no para los incrédulos.

5. Conf. X, 6, 10: PL 32, 783 y passim. 
El otro aspecto del método agustiniano en este tema, como el de toda meditación filosófica acerca de Dios, nos lo ha señalado también repetidamente el propio Agustín. Se trata de la "ascensión gradual" de las cosas hasta Dios. A Dios nadie lo ha visto nunca. Por eso toda meditación filosófica sobre él tiene que partir de lo visible; consiste en la gradual ascensión de lo imperfecto a lo perfecto, de lo mudable y corruptible al Inmutable e Incorruptible. El punto privilegiado de arranque es el hombre y el eterno tema de estudio es la antropología. Pero tampoco hemos de despreciar o infravalorar el mundo exterior visto por el hombre: "ab exterioribus ad interiora, ab interiore ad superiora". Esta ascensión gradual, que se basa en una visión jerárquica de los seres, está ya insinuada en las primeras obras de San Agustín ${ }^{6}$, la explaya con bastante amplitud en De Musica, De Libero Arbitrio y De Vera Religione ${ }^{7}$ y es, finalmente, completada en las obras cumbres de la madurez ${ }^{8}$. Agustín la atribuye fundamentalmente a los platónicos, pero él la elabora siempre a su modo .

Sin duda el texto más típico lo encontramos en el libro décimo de las Confesiones. Comienza con una solemne profesión de sinceridad, pues habla ante "Aquel a cuyos ojos está siempre desnudo el abismo de la conciencia humana"; después invoca a Dios, fuente de toda verdad, para descubrirla en sí mismo y comunicarla luego a los hermanos con los que está unido por la caridad de Cristo. Algo sabe ya de Dios, que constituye el objeto de su amor; quiere perfeccionar este conocimiento habitual y natural valiéndose de las criaturas que le hablarán de su Creador, "quiere ascender por grados hacia Aquel que le hizo". Todas las cosas -el mar, la tierra, el aire...- le descubren facetas del Hacedor y le invitan con su presencia muda y elocuente al conocimiento, a la alabanza y al amor al Padre común: "El nos ha hecho", claman con potente voz. Especialmente el análisis del ser humano, - "que sobrepuja a sí mismo, que no cabe dentro de sí mismo..."-, el camino interior propio de

6. Cf. Sol. I, 13, 23: PL 32, 882; De Beata vita 4, 35: PL 32, 976; De Quant. an. 33, 70-76; 35, 79: PL 32, 1075-1079...

7. De Mus. VI, 1, 1; 2,2; 16, 21: PL 32, 1161, 1163, 1189; De Lib. arb. II, 3, 7-15, 20: PL 32, 1243-1263; De Vera Rel. cap. 29-31; 41, 77, etc.: PL 34, 145-8, 156.

8. Conf. VII, 17, 23; IX, 10,24s; $\mathrm{X}, 6$, 8ss. passim: PL 32, 745, 774, 782-3; De Trin. VI, 10, 12; XV, 2, 3, etc.: PL 42, 932, 1058; De Civ. Dei VIII, 6; XI, 2; XI, 16: PL 41, 231, 317-8, 331.

9. De Civ. Dei VIII, 6: PL 41, 231. 
un "hombre moderno", le sirve para descubrir y ascender al Creador ${ }^{10}$.

Es claro que la senda hacia Dios es siempre misteriosa y la búsqueda ha de ser constante ${ }^{11}$. Muchas expresiones tendrán incluso un sentido más simbólico que literal, serán más atisbos que demostraciones y hay más preguntas que respuestas. Pero aun así, Agustín insiste en descubrir y analizar en el mundo las huellas divinas. Su investigación comienza por lo más obvio y elemental, donde Dios se manifiesta al hombre de modo más imperfecto, para ascender gradualmente a los seres superiores, en los que Dios se expresa con mayor nitidez. El comenzar por los seres inferiores tiene, sin embargo, la ventaja de una mayor sencillez y más fácil acceso ${ }^{12}$.

Si nunca podemos agotar con nuestro pobre conocimiento la inmensa y variada riqueza de la realidad mundana, si las cosas más ordinarias ya aparentemente triviales nos ofrecen siempre renovados motivos de asombro, mucho menos podemos adquirir un concepto cabal y exacto del Creador. Con todo, al descubrir en el mundo los "vestigios trinitarios" se esclarece débilmente nuestra comprensión humana del misterio divino o podemos vislumbrar una confirmación de los datos recibidos por la fe, a la vez que se ilumina y se transfigura nuestra visión del mundo. En realidad, como

10. Conf. X, passim: PL 32, 780ss. Cf. R. Florez, Presencia, 67-101.

11. "Trinitatem certe quaerimus, non quamlibet, sed illam Trinitatem quae Deus est, verusque ac summus et solus Deus. Expecta ergo, quisquis haec audis: adhuc enim quaerimus, et talia quaerentem nemo juste reprehendit... Cognitio certa non perficietur, nisi post hanc vitam, cum videbimus facie ad faciem. Hoc ergo sapiamus, ut noverimus tutiorem esse affectum vera quaerendi, quam incognita pro cognitis praesumendi. Sic ergo quaeramus tanquam inventuri: et sic inveniamus, quanquam quaesituri" (De Trin. IX, 1, 1: PL 42, 960-1). "Videtur enim, quod semper quaeritur, nunquam inveniri... et tamen Dominum Deum inveniri posse dum quaeritur, testatur Isaias propheta: Quaerite facien eius semper. An et inventus forte quaerendus est? Sic enim sunt incomprehensibilia requirenda, ne se existimet nihil invenisse, qui quam sit incomprehensibile quod quaerebat, potuerit invenire. Cum ergo sic quaerit, si incomprehensibile comprehendit esse quod quaerit, nisi quia cessandum non est, quamdiu in ipsa incomprehensibilium rerum inquisitione proficitur, et melior meliorque fit quaerens tam magnum bonum, quod et inveniendum quaeritur, et quaerendum invenitur? Nam et quaeritur ut inveniatur dulcius, et invenitur ut quaeratur avidius" (Ib. XV, 2, 2: PL 1057-8).

12. "Illo ipso ordine conditionis nostrae quo mortales atque carnales effecti sumus, facilius et quasi familiarius visibilia pertractamus..." (De Trin. XI, 1,1: PL 42, 984-5). "Assuescat in corporalibus ita spiritualium reperire vestigia, ut cum inde sursum versus duce ratione ascendere coeperit, ut ad ipsam incommutabilem veritatem per quam sunt facta ista perveniat, non secum ad summa pertrahat quod contemnit in infimis..." (Ib. XII, 5, 5; XIV, 7, 9-10: PL 1001, 1043-4). 
veremos, lo que queda más iluminado no es el misterio de Dios, sino el misterio del mundo y de la existencia humana.

\section{Creación y semejanza}

El primer fundamento para establecer las huellas divinas o los vestigios trinitarios en las cosas nos viene dado por el concepto clave de creación, idea, verdaderamente fundamental, ajena a toda las antiguas y modernas filosofías y que se introduce en la historia del pensamiento con el judaísmo y con el cristianismo.

De forma reiterativa y constante afirma Agustín esta primera y radical verdad de fe en varios tonos y matices y en innumerables textos que es imposible transcribir. $Y$ él contribuyó como nadie a precisar y elaborar filosóficamente el concepto de creación "ex nihilo sui et subjecti" ${ }^{13}$. Hoy todos sabemos, aunque no la comprendamos en sí misma, lo que creación significa: producción total del ser; el ser todo de la criatura es total y gratuita donación de Dios sin que ella de por sí posea absolutamente nada. Se excluye primero toda clase de emanatismos o panteísmos: lo preducido no es Dios. Se excluye también toda clase de materia preexistente increada: incluso la materia informe es creada. Finalmente, la creación es para Agustín obra exclusiva de Dios: sólo él puede crear ${ }^{14}$.

Del concepto mismo de creación brotan espontáneas una serie de consecuencias y se derivan unos lazos característicos entre el Creador y la criatura ${ }^{15}$. Aquí nos interesa considerar la criatura

13. J. O.'Toole, The Philosophy of Creation in the Writings of St. Augustine (Washington 1944); $\mathrm{H}$. HEIMSOETH, Los seis grandes temas de la metafisica occidental (Madrid 1946) 37-40; A.-D. SerTILlanges, El Cristianismo y las filosofias (Madrid 1966) I, 59-62, 236-40, 312-21; C. TRESmontant, La Métaphysique du Christianisme et la naissance de la philosophie chrétienne (Paris 1961) 27-242. Para la bibliografía sobre el tema de la creación en San Agustín, cf. T. VAN BAVEL, Répertoire bibliographique de Saint Augustin (Louvain 1963) núms. 2645-2702.

14. Conf. XI, 5, 7; XII, 7, 7; XIII, 33, 48: PL 32, 812, 828, 866; De Trin. III, 8, 13-9, 18, etc.: PL 42, 875-879.

15. Por ejemplo, las cosas son productos de Dios (aunque no debemos aplicar aquí la noción de causalidad eficiente al modo como la vemos realizada en el mundo). A este respecto es central en el pensamiento agustiniano el concepto de participlación (cf. De Div. Quaest. 83, q. 54: PL 40, 38; De Vera Rel. 18, 35: PL 34, 137; Conf. VII, 14, 20ss; XI, 4, 6: PL 32, 744, 811; De Civ. Dei XII, 5: PL 41, 352-3; F. J. THonNARd, "Caractéres platoniciennes de l'ontologie augustinienne": Augustinus Magister I (Paris 1955) 317-27; F. CASADo, "El Ser (Dios) y el ser-no-ser (criaturas) en la metafísica agustiniana"; La Ciudad de Dios 73 (1957) 5-18). 
como un "vestigio" del Creador. Con frecuencia, al hablar de la creación, se ha insistido casi exclusivamente en lo que, de un modo muy amplio, podríamos denominar causalidad eficiente. Pero en la perspectiva agustiniana tenemos que resaltar tanto o más la causalidad formal o ejemplar. Precisamente una de sus tesis típicas es lo que se ha llamado el "ejemplarismo" ${ }^{16}$. Procedencia y semejanza son en sí mismos dos conceptos distintos y no siempre van unidos. En el presente caso representan dos aspectos complementarios de la misma obra creada. Este último aspecto, es decir, la doctrina de Dios como "modelo" y el mundo como "copia", "vestigio" o "semejanza" de Dios es ciertamente la más tratada por Agustín. En las cosas creadas deben de algún modo manifestarse las huellas divinas, afirma constantemente. De tal modo todo es vestigio de Dios que incluso el pecado - repite con frecuencia Agustín- pretende a su manera ser también imitación de algo divino ${ }^{17}$. Expresión y creación vienen, pues, a ser como dos conceptos convertibles, como dos caras de la misma obra de Dios. Somos creados en cuanto expresamos a Dios y expresamos a Dios en cuanto somos creados. Dicho de otro modo: la creación es la manera como Dios se expresa fuera de sí mismo ${ }^{18}$.

Se da también una constante dependéncia de la criatura respecto al Creador. No sólo el ser creado, sino su obrar se ejecuta siempre en tanto que Dios existe, si bien en un primer plano fenomenológico se mantenga la autonomía de lo creado (De Trin. III, 4,9: PL 42, 871-3; De Gen. ad Litt. IV, 12, 22-23: PL 34, 304-5). Señalemos también como fundamental e inmediata consecuencia de la creación la bondad dé la criatura, que Agustín afirma constantemente contra los maniqueos (Cf. sobre todo $D e n a-$ tura boni: PL 42, 551-572; J. Hessen: "Die axiologische Konsequenz der Schöpfungsidee ist demach ein universeller Seinsoptimismus" (Platonismus und Prophetismus (München 1939, 151). Quisiéramos insistir una vez más que cuando hablamos de "causalidad" o de "consecuencias" refiriéndonos al Creador y a las criaturas hemos de entenderlo en sentido muy amplio. En el concepto mismo de creación negamos el "principium coniunctum" para hablar únicamente de "palabra creadora". No hay conexión necesaria entre causa y efecto. Sciacca dice, con razón, que "el Creador es principio primero, pero no causa primera del ser creado" (M. F. Scracca, Ontologia, 65-71).

16. De Div. Quaest. 83, q. 46: PL 40, 30-4. Cf. A. Solignac, "Analyse et sources de la Quaestion 'De Ideis" ": Augustinus Magister I (Paris 1955) 307-15: H. MEYERHOFF "On the Platonism of the Augustine's Quaestio De Ideis": The New Scholasticism 16 (1942) 16-42.

17. "Perverse te imitantur omnes, qui longe se a te faciunt et extollunt se adversum te. Sed etiam sic te imitando indicant creatorem te esse omnis naturae et ideo non esse, quo a te omni modo recedatur" (Conf. II, 6, 13-14: PL 32, 680-1; De Vera Rel. cap. 39-54: PL 34, 150-168, etc.).

18. H. E. Hengstenberg, Das Band, 149. En realidad todos los Padres interpretan la creación dentro de la teoría platónica de modelo-copia. 
De nuevo recoge Agustín tradiciones bíblicas y filosóficas. La creación es una verdad revelada, hemos dicho. Pero Agustín está también influenciado por la filosofía - por el platonismo especialmente - y conforme a ello intenta esclarecer e interpretar la revelación. El mismo cree que los platónicos lograron alcanzar el concepto preciso de creación. Si bien Agustín está equivocado a este respecto, lo cierto es que algunas ideas platónicas le sirvieron para interpretar la Biblia y que una vez más nos encontramos con la unión de helenismo y profetismo. En efecto, la Biblia habla del hombre como imagen y semejanza de Dios, Platón habia enseñado que el mundo terrestre es imitación del celeste, Filón de Alejandría insistió en que el mundo de las ideas hay que colocarlo en Dios, Plotino había escrito páginas sugestivas sobre el particular, afirmando de modo panteístico que las tres hipóstasis estaban inmanentes en las cosas... Agustín traspone, perfecciona, matiza y aplica las ideas platónicas y plotinianas y las transforma dentro de moldes cristianos. Las cosas están hechas conforme a las ideas divinas, al Verbo de Dios; existen porque Dios las ve y tal como El eternamente las ve ${ }^{19}$.

\section{Semejanza en la desemejanza}

Pero el concepto de creación es algo netamente nuevo dentro de las categorías filosóficas griegas. Por eso, aunque la relación de semejanza (modelo-copia) es una relación original, cualitativamente distinta de la relación causal en sentido propio, también aquí tenemos que decir que esta relación es aplicable a Dios sólo de manera análoga y remota. Dios se expresa en la creación de un modo enteramente superior a todas las expresiones de las criaturas: del espíritu en la materia, del artista en su obra, o del padre en el hijo. Nuestra noción ordinaria de causalidad ejemplar no podemos, pues, aplicarla a Dios tal como se nos presenta en los fenómenos concretos de nuestra experiéncia mundana. $Y$ como la experiencia es una fuente imprescindible para la formación de nuestros conceptos filosóficos, es preciso un esfuerzo no pequeño para superar la visión inmediata que nos ofrecen los datos sensibles, o

19. Cf. C. P. MAYER, Die Zeichen in der geistigen Entwicklung und in der Theologie des jungen Augustinus (Würzburg 1969) 271-84. 
al menos ser conscientes de nuestros inevitables antropomorfismos (o "cosmomorfismos") cuando hablamos del Dios trascendente. Ya que ninguna criatura puede compararse a Dios, el concepto de semejanza es necesariamente análogo o -dicho en palabras de Agustín - se trata siempre de una "semejanza en la desemejanza" ${ }^{20}$.

Se ha repetido con frecuencia que los dos pilares en los que descansa la doctrina agustiniana sobre Dios son la trascendencia y la inmanencia, auténticas y recíprocamente implicadas. Dios es a la vez "intimior intimo meo et superior summo meo" ${ }^{21}$. La creación rechaza la inmanencia total, panteística, de Dios que aparece como "totalmente Otro" frente al mundo. Pero a la vez Dios y el mundo mantienen una cierta unidad de sentido: Dios está misteriosa e íntimamente presente en él: "Non ergo essem, Deus meus, non omnino essem ni esses in me..." ${ }^{22}$. Según esto, observa atinadamente Gilson, que es precisamente el concepto de semejanza quien tiene el papel de intermediario, término medio entre la identidad y la alteridad exclusivas ${ }^{23}$. Efectivamente, al igual que en Platón, la imagen y semejanza tienen en Agustín una función mediadora.

La diferencia más importante entre la semejanza de Dios expresada en la creación y las diversas semejanzas o expresiones que encontramos en nuestro mundo empírico, consiste en que éstas requieren necesariamente un material previo, mientras que Dios no lo requiere. Es decir, las criaturas sólo pueden expresarse a través de algún "medio"; en cambio Dios no necesita de ningún medio para expresarse, como se deduce del concepto mismo de creación "ex nihilo". La misma criatura es "semejanza" de Dios, "expresión" de una idea divina, "eco" de su voz. Dios se manifiesta de un modo absolutamente pleno, sin dependencia de una materia anterior.

20. La semejanza perfecta del Padre es el Hijo; las demás cosas son en parte semejantes $\mathrm{y}$ en parte desemejantes (De Gen. ad Litt. imperf. lib. 16, 60: PL 34, 243-4).

21. Conf. III, 6, 11: PL 32, 688.

22. Conf. I, 2, 2: PL 32, 661. Cf. R. FLoREZ, Las dos dimensiones del hombre agustiniano (Madrid 1958) 43-50.

23. E. GILson, Introduction a l'étude de Saint Augustin 3 ed. (Paris 1949) 275-85. Las cosas son y no son a la vez: son en cuanto se asemejan al Creador y no son en cuanto se desemejan de El. Es claro que en la semejanza, como en el ser, hay diversos grados ("aliis dedit esse amplius, aliis minus; atque ita naturas essentiarum gradibus ordinavit" - $D e$ Civ. Dei XII, 2: PL 41, 350), desde la materia informe ("tanto a te longius quanto dissimilius"- Conf. XII, 7, 7: PL 32, 828) hasta el espiritu elevado que, además de semejanza, es "imagen". 
Por eso su expresión es más personal: las mismas personas de la Trinidad son las que se expresan en las criaturas.

La semejanza divina debe ser comprendida a la luz de la revelación. Según ésta, tenemos una expresión de Dios hacia dentro -en el seno de la Trinidad-, y otra hacia fuera -en las criaturas-. En el interior de la Trinidad comunica Dios su propia esencia, en el exterior comunica sólo un modelo o semejanza de su esencia ${ }^{24}$. Dios crea con entera libertad y sin perder absolutamente nada de su ser soberano; y a la vez expresa en la creación su triple personalidad, según las propiedades de las tres Personas divinas, que llamamos "atribuciones".

\section{Las huellas divinas de la unidad.}

En Dios hay una infinita plenitud de realidad que es su misma vida trinitaria, sin menoscabo alguno de su absoluta y simplicísima unidad. Dentro del misterio cristiano Dios es uno - "único"en esencia y trino en personas. Las criaturas - que son participación del ser divino- manifiestan a su modo la unidad y la trinidad, que se convierten para nosotros en auténticos "principios del ser creado" ${ }^{25}$. Sabido es que los Padres griegos, partiendo de la Trinidad de personas en Dios, intentaron aclarar el misterio del DiosUno; San Agustín parte decididamente de la unidad de la naturaleza divina para aclarar el misterio del Dios-Trino. También en la creación hemos de comenzar por la unidad.

Este tema de la unidad, viejo ya en la historia de la filosofía desde los presocráticos hasta Plotino, es también básico en la doctrina agustiniana, ya que Agustín lo reasume y reelabora personalmente para sus fines teológicos. $Y$ lo que a veces había sido una simple especulación abstracta, para Agustín se convierte en una

24. H. E. Hengstenberg, Das Band, 150ss, 172.

25. Algunas de estas ideas las toma Agustín, a veces literalmente, de Plotino. Mas no hemos de dejarnos engañar por las apariencias, ya que todo hay que enmarcarlo dentro del concepto básico y angular de la creación. No estamos en una emanación panteísta; la unidad y la trinidad de Agustín son una participación análoga y remota de la suprema unidad y trinidad del Creador, no hipóstasis subsistentes en las cosas. Con todo, el ejemplo de Plotino al buscar en las cosas las tres hipóstasis y poner al Uno como principio sin principio de la emanación universal sirvió de ejemplo a Agustín, el cual, hecha la transferencia de las doctrinas plotinianas al cristianismo, intenta verificar también él la presencia de las divinas personas y de la naturaleza divina en los entes del mundo. 
experiencia real y concreta desde el momento en que él había vivido larga y profundamente el dualismo maniqueo. La lectura iluminadora -y con ojos cristianos- de las obras de los neoplatónicos por la que supera el dualismo maniqueo, logra también que el tema de la unidad se convierta en algo central de la metafísica agustiniana ${ }^{26}$.

Lógicamente en la primera época posterior a la conversión, mantiene Agustín un concepto neoplatónico del ser, que lo identifica con la unidad. El fundamento y razón de todo ser es la unidad, que en su más alto grado se identifica con Dios, el Creador. En tanto algo es, en cuanto es uno: "Porque la perversión es destrucción del orden, la tendencia al ser es tendencia al orden... El orden reduce a una cierta unidad lo que organiza. La esencia del ser es la unidad y en la misma medida que es uno es ser; mientras que las cosas simples son por sí mismas, pues ellas son la unidad, las que no lo son imitan esta unidad por la concordia de sus partes y la medida de su unión es la medida de su ser" ${ }^{27}$. "Para que la piedra, el árbol, el animal o el amor entre dos personas, el pueblo o el ejército existan es necesaria la unidad" ${ }^{28}$. Todas las cosas buscan, pues, ineludiblemente la unidad, tanto los seres animados como los inanimados; todos tienden espontánea y necesariamente a conseguir la mayor unidad posible: "No hay cosa, aunque privada del poder de gozar o sufrir, que no tenga la unidad propia del modo de su especie como requisito de su estabilidad natural. No hay ser que buscando el deleite o huyendo de la pena, no apetezca la unidad en la huida del dolor y en la búsqueda del gozo" ${ }^{29}$. La unidad entra en lo constitutivo del ser y es principio de la acción, de la verdad, de la belleza y del orden: "Si te agrada la armonía es porque tiene unidad", "la forma de toda hermosura es la unidad" " ${ }^{30}$ La unidad da consistencia, estabilidad y funda el instinto de pervivencia: "No hay absolutamente ningún cuerpo desprovisto de ciertos vestigios

26. Cf. E. MülleR, Augustins Lehre, 4-7; Gilson, Introduction, 277-8; C. Vicente, La unidad en las doctrinas de San Agustin (Manila 1950; Tesis doctoral, dact.); ID., "La unidad metafísica según San Agustín": Religión y Cultura 1 (1956) 593-609.

27. De Mor. manich. II, 6, 8: PL 32, 1348.

28. De Ord. II, 18, 48: PL 32, 1017.

29. De Lib. arb. III, 23, 70: PL 32, 1305; De Gen. ad Litt. imperf. lib. 10, 32: PL 34, 233.

30. De Vera Rel. 32, 59-60: PL 34, 148-9; De Gen. c. Manich. I, 21, 32: PL 34, 188-9; Epist. 18, 2: PL 33, 85. 
unitarios... Todo lo que consigue perfección y estabilidad es gracias a la unidad" ${ }^{31}$.

Especialmente relaciona Agustín la unidad con la forma y el orden, que constituye respectivamente el segundo y tercer momento de la dialéctica de la creación y que son simple desarrollo de la unidad, ley y energía del ser ${ }^{32}$. Así al hablarnos de la formación afirma que el "dar forma no es sino reducir a unidad" ${ }^{33}$. Y en otra parte: "omnis forma ad regulam cogitur unitatis" ${ }^{34}$. Agustín da un paso más insistiendo en que la unidad y la formación son vestigios divinos y proceden del Dios creador, "al cual pertenece reducir a unidad las extensiones, y dar fluencia a los tiempos y hacer que cada cosa sea específicamente una. El es el Uno soberano y, llenándolo todo, de él reciben unidad semejante las cosas que reciben forma" ${ }^{35}$. Y como la formación es atribuída al Verbo, añade Agustín: "De tal modo, Dios mío, penden de tu Verbo las informidades que, si él no las trajera a unidad formándolas, quedarían lejos de ser y de ser buenas" ${ }^{36}$.

De modo semejante relaciona Agustín la unidad con el orden, que es el tercer momento de la dialéctica creacional y otro de los trascendentales de la ontología augustiniana. Como hemos visto en textos anteriores, distingue Agustín la unidad de cada cosa en si misma y la unidad de todas las cosas en la superior totalidad del cosmos: "universum ab unitate nomen accepit" ${ }^{37}$. Agustín establece la jerarquía de los entes a base de su mayor o menor grado de unidad. La jerarquía ha de abarcar desde el Ser supremo hasta la

31. De Vera Rel. 32, 59-60: PL 34, 148-9; De Lib. arb. III, 23, 70: PL 32,1305

32. Mejor que hablar de "dialéctica" -que de ordinario se entiende como un proceso necesario - sería preferible hablar de "dialógica", en cuanto la creación brota de un acto libérrimo de Dios. En todo caso Agustín habla de un proceso que se realiza en tres momentos lógicos: la creación inicial de la materia informe que atribuye al Padre; la formación o impresión de esencia que atribuye al Hijo, y la ordenación o dotación de existencia real dentro del conjunto que atribuye al Espíritu. Cf. L. Cilleruelo, "La formación del cuerpo según San Agustín": La Ciudad de Dios 66 (1950) 445-473; A. ESPADA, "Introducción a la dialéctica de San Agustín": Estudio Agustiniano 3 (1968) 55-79.

33. Dé Gen. ad Litt. imperf. lib. 10, 32: PL 34, 233.

34. De Gen. c. manich. I, 12, 18: PL 34, 181.

35. De Vera Rel. 43, 81: PL 34, 159; De Lib. arb. II, 17, 45-6: PL 32, 1265; Conf. I, 20, 31: PL 32, 675.

36. Conf. XIII, 2, 2-3: PL 32, 845 .

37. De Ord. II, 18, 48: PL 32, 1017; De Gen. c. manich. I, 21, 32: PL 34,189 . 
nada. Después de la nada, vendría la materia informe, ese "prope nihil" misterioso y que, en cuanto algo procede de Dios ${ }^{38}$. Pero de hecho los entes son "formados" y dentro de estos entes el grado ínfimo le corresponde al cuerpo inanimado: no tiene propiamente unidad y el espíritu se engaña cuando considera como unidades reales a los cuerpos divisibles en el espacio. Tales cuerpos sin embargo son semejantes a la unidad, tienen una "ley de cristalización"; se esfuerzan por conseguir la unidad, pero no la logran, pues si la lograsen ya no serían cuerpo, sino que habrían subido al grado superior del ser en que no hay división espacial ${ }^{39}$. Superiores son los organismos, no sólo porque ya no se pueden dividir en otros organismos sin perder su esencia orgánica, sino también porque ellos crean sus unidades y así se subordinan a la acción y virtud de la idea unitaria del mundo. Hay aquí algo más que una "ley de cristalización": hay vida, "ley vital"

La unidad, como todo lo originario, es a la vez lo primero y lo último, punto de partida y meta de conquista para el hombre, camino a recorrer en su ascensión al Padre, "de quien recibe la unidad todo lo que de algún modo es uno" " ${ }^{41}$. En las criaturas hay una unidad inicial, que es punto de partida de su ser y de su operación, y una unidad final, terminal, que es la unidad lograda en el orden universal del cosmos. Esta constituye el más alto bien al que aspiran todos los entes. Y como la característica más destacada de las criaturas es el tiempo y la mutabilidad, y es imposible lograr una perfecta unidad fuera del Dios eterno e inmutable, el devenir de las criaturas es siempre un oscilar entre el ser y el no-ser, un antagonismo entre el ser y la nada.

Aunque en sus largas meditaciones sobre la materia informe queda relativizado el concepto neoplatónico del ser como reductible a unidad, Agustín sigue manteniendo sus principios básicos: todos los entes creados son unos por participación, según los diversos grados y formas de unidad; la unidad de las criaturas proclama la unidad del Creador ${ }^{42}$. Al principio Agustín defiende la unidad divina contra el dualismo maniqueo de los dos principios; después la

38. Conf. XII, passim: PL 32, 825-844.

39. De Vera Rel. 32, 59-60: PL 34, 148-9. 9-10.

40. De Ord. II, 18, 48: PL 32, 1017. Cf. E. MüLLER, Augustins Lehre,

41. De Vera Rel. 36, 66: PL 34, 151; Conf. XII, 28, 38: PL 32, 842.

42. De Lib. arb. III, 23, 70: PL 32, 1305. 
inserta en sus teorías trinitarias. Así como en el mundo la unidad to invade todo y es principio de belleza y de orden, así de modo eminentísimo en Dios: el Padre es principio sin principio; el Verbo no es degeneración del Padre (como en el neoplatonismo), sino que refleja al Padre en perfecta unidad de esencia; el Espíritu es igual al Padre y al Hijo, de los que procede como lazo de amor y de unidad. Dios es no sólo uno, sino Unico.

Agustín concibe a Dios como vivo, vida de toda vida ${ }^{43}$. $\mathrm{Si}$, como habían afirmado los platónicos, Dios posee todas las propiedades positivas de la naturaleza y del hombre, ¿cómo podría carecer de vida? ${ }^{\star 4}$. Dios obra como vivo y por medio de su Verbo. Dios no ve las cosas aisladas, sino de una vez, y las expresa en su Verbo; no emana de él la multiplicidad en el pensamiento, en la palabra o en la acción, como en el hombre, sino que su unidad permanece inalterable. En el Verbo se contienen los principios formales de todas las cosas por ser la Forma original,en él está contenida la idea del mundo como "pensamiento de Dios" ${ }^{15}$. Tal idea del mundo entra en la unidad y las cosas han de encuadrarse en esa idea del mundo y en cuanto se ordenan en ella son semejantes a la Unidad ${ }^{16}$. El Espíritu Santo sirve a su vez de lazo de unión en el seno de la Trinidad como Amor entre el Padre y el Hijo; de lazo también de unidad dentro del cosmos manteniendo la estabilidad y el orden; y finalmente, de lazo entre Dios y el mundo ${ }^{47}$. Así el mundo no es sólo una unidad ideal en la mente de Dios, sino una realidad trascendente a Dios, que forma un cosmos, una unidad armónica, obrada por el "mundus intelligibilis", pensamiento divino del Hacedor, y colocado en la existencia por su voluntad y amor gratuito. Ese cosmos noetos es la razón de ser de lo real y la meta de la evolución del mundo entero ${ }^{48}$.

En síntesis, podemos concluir que según San Agustín todos los seres brotan de la unidad originaria del Padre, son formados (es decir, "recogidos en unidad") por el Verbo, y son mantenidos y restituidos a la unidad final por la fuerza del Espíritu. Cada cosa indi-

43. Conf. X, 6, 10: PL 32, 783, et passim.

44. Ser. 127, 6, 9: PL 38, 710.

45. Ser. 117, 2, 3: PL 38, 662-3.

46. De Vera Rel. 43, 81: PL 34, 159.

47. H. E. Hengstenberg, Das Band, 186-96; Conf. XIII, passim: PL 32, 846ss.

48. Retract. I, 3, 2: PL 32, 588-9; E. MÜLLER, Augustins Lehre, 9-12. 
vidual, y todas juntas formando el universo, constituyen un "vestigium" de la UNIDAD del Creador. Agustín había partido de la fórmula griega: Crea el Padre por el Hijo en el Espíritu Santo. Por significa principio eficiente y formal ("Virtus et Sapientia Dei"); En significa "orden" que brota del plan divino, en el que cada cosa tiene su puesto y función, su sentido y valor. Agustín acentúa el carácter dinámico y relacional de su ontología.

\section{Los vestigios trinitarios.}

Lo mismo que la unidad, también la trinidad se convierte en "principio del ser creado". Todo ser, en la medida en que es, tiene primero una cierta unidad, segundo una cierta forma - por la que tiene parte en el conocimiento, ya sea conociendo si es espíritu, ya dándose a conocer al espíritu ${ }^{49}$ - y tercero una voluntad y amor por el que se esfuerza en perfeccionarse: esse, nosse, velle; unitas, species, ordo ${ }^{50}$.

Si todo es criatura de Dios, si el cielo y la tierra y el mar y el aire anuncian clamorosamente que son hechuras suyas, ellas mismas tienen que reflejar los vestigios trinitarios: el cielo y la tierra claman que han sido hechos porque se mudan y cambian... Los hizo el Señor que imprimió en ellos las características de su propio ser trinitario ${ }^{51}$.

Partiendo de la Trinidad busca Agustín comprender la estructura misma del ser creado, en el que encuentra múltiples huellas o vestigios divinos. "El universo agustiniano tiene su estructura metafísica de una participación compleja en la naturaleza del ser divino, que se funda ella misma en las relaciones trascendentales de las personas divinas entre ellas mismas" ${ }^{52}$. Las huellas trinitarias en las cosas son analizadas por Agustín desde el primer momento de su carrera de escritor. Conservando siempre la unidad de la operación divina "ad extra" común a las tres Personas, se realiza una

49. De Civ. Dei XI, 27, 2: PL 41, 341.

50. De Trin. VI, 10, 12: PL 42, 932, etc. Cf. nota 64 .

51. Conf. X, 6, 9; XI, 4, 6; XIII, 5, 6: PL 32, 783, 811, 847.

52. E. Gilson, Introduction, 281. "Von der Trinität her sucht Augustin das Wesen der geschaffenen Substanz zu fassen" (R. ScHNErder, Das Wandelbare Sein. Die Haupthemen der Ontologie Augustins (Frankfurt am M., 1938) 17. 
suerte de dialéctica creacional trinitaria que, proveniente de Dios, ha dejado marcado su sello en la criatura ${ }^{53}$.

Prescindiendo de otras insinuaciones de primera época ${ }^{54}$, encontramos un texto básico en una Carta dirigida a Nebridio. El "dulce amigo, ardentísimo investigador de la verdad" ${ }^{5}$, le había planteado, según su costumbre, múltiples cuestiones difíciles, algunas acerca de la Encarnación y de la Trinidad. Agustín aún no ha penetrado lo suficiente en la doctrina cristiana y se equivoca en la inteligencia de ambos misterios, como reconocerá posteriormente ${ }^{56}$. Pero es interesante la explicación que ofrece: "No existe naturaleza alguna, dice, que no contenga estos tres elementos: el ser, el ser esto o lo otro, la permanencia en su ser... $Y$ como estos aspectos se dan indisolublemente unidos, así se comprende con cuánta verdad entiende la religión católica la inseparabilidad de la Santísima Trinidad" ${ }^{57}$.

Nuevo paso en De Vera Religione. La obra está dirigida a Romaniano $y$, agradeciéndole los favores que de él ha recibido, quiere demostrarle la armonía entre la filosofía y la religión. Los fundamentos de la verdadera religión son la historia y las profecías. Creídas las Escrituras, la mente debe irse purificando para entender. La primera verdad que tenemos que admitir es la existencia del Dios inmutable Uno y Trino. "Conocida esta Trinidad se ve que toda criatura inteligente, animada o corporal, de la misma Trinidad creadora recibe el ser en cuanto es, y tiene forma y es administrada con perfecto orden; mas no por eso vaya a entenderse que una porción de

53. Conf. XIII, 5, 6: PL 32, 847: De Gen. ad Litt. I, 6, 12; II, 6, 14: PL 34, 251, 268. Agustín insiste en la unidad de las operaciones divinas "ad extra" común a las tres divinas personas. Hace suya, como hemos dicho, la fórmula de los Padres griegos: Crea el Padre por el Hijo en el Espíritu Santo: "(Omnia) Pater per Filium in Spiritu Sancto (fecit). Trinitas est; sed una operatio, una maiestas, una aeternitas" (Ser. 126, 8, 10: PL 38, 703; De Gen ad Litt. I, 6, 12; II, 6, 10-14; III, 19, 29; 20, 30-32: PL 34, 250-1, 267-9; 291-3; Conf. XIII, 22, 32: PL 32, 858-9. Cf. A. TurraDo, Dios en el hombre. Plenitud o tragedia. (Madrid 1971) 99-100, con multitud de textos agustinianos. Sobre la dialéctica trinitaria en la creación, cf. nota 32 ).

54. J. RIEF, Der Ordo Begriff des jungen Augustinus (Paderborn 1962) 196; F. CAVALLERA, "Les premières formules trinitaires de saint Augustin”, Bulletin Litt. Eccl. 31 (1930) 97-123; O. DU RoY, L'intelligence de la foi en la Trinité selon saint Augustin. Genèse de sa Théologle trinitaire jusqu'au 391 (Paris 1966).

55. Conf. IX, 3, 6: PL 32, 765.

56. Conf. VII, 19, 25: PL 32, 746. Cf. nota 54.

57. Epist. 11, 3: PL 33, 76. 
criatura la hizo el Padre y otra el Hijo y otra el Espíritu Santo... Toda sustancia es algo único, difiere por su forma de las demás, y está dentro del orden universal" 58 .

Por la misma época escribe Agustín De Diversis Quaestionibus 83, en que nos encontramos con un texto preciso y luminoso: "Omne quod est, aliud est quo constat, aliud quo discernitur, aliud quo congruit. Universa igitur creatura si et est quoquo modo, et ab eo quod omnino nihil est plurimum distat, et suis partibus sibimet congruit, causam quoque eius trinam esse oportet; qua sit, qua hoc sit, qua sibi amica sit. Creaturae autem causam, id est, auctorem Deum dicimus. Oportet ergo esse Trinitatem, qua nihil praestantius, inteIligentius et beatius invenire perfecta ratio potest. Ideoque etiam cum veritas quaeritur, plus quam tria genera quaestionum esse non possunt; utrum omnino sit, utrum hoc an aliud sit, utrum approbandum improbandumve sit" ${ }^{5}$.

Poco a poco Agustín va avanzando en sus meditaciones y precisando las diferencias entre "imagen", "semejanza", "vestigio". Toda imagen ha de ser semejante, pero no viceversa ${ }^{60}$. A la vez perfecciona y amplía sus tríadas, sin abandonar nunca las conquistas realizadas. En la misma obra anteriormente citada nos dice que todo es bueno y que todo es imitación a semejanza de Dios, más o menos según los diversos grados de participación en el ser, en la vida y en la inteligencia. Pero hay que distinguir claramente estas tres cosas: la "semejanza sustancial" del Padre que es su Hijo, Dios como El; las cosas todas que son semejantes al Hijo, hechas por el Verbo, "per Imaginem", y el espíritu humano, creado a imagen y semejanza de Dios, "ad imaginem" ${ }^{61}$.

En De Genesi ad Litteram imperfectus liber insiste - contra el materialismo maniqueo - en que la Trinidad se refleja propiamente en el alma. Sólo la sustancia racional fue hecha "per Imaginem" (causa eficiente) y "ad Imaginem Dei" (causa formal). Sin embargo, admite que en todas las cosas se percibe el sello de la unidad, hermosura y orden como reflejo lejano del Dios Uno y Trino ${ }^{62}$.

58. De Vera Rel. 7, 12-3. Cf. 11,$21 ; 12,24 ; 44,82$ : PL 34, 128-9, 131$2,159$.

59. De Div. Quaest. 83, q. 18: PL 40, 15.

60. Cf. R. A. Markus, "Imago and Similitudo' in Augustine": Rev. des Etudes August. 10 (1964) 125-145.

61. De Div. Quaest. 83, q. 51, 2-4: PL 40, 32-3.

62. De Gen. ad Litt. imperf. lib. 16, 59-60. Por eso, cuando aquí nos dice que sólo el alma es "semejante" a Dios, hay que entender la palabra 
Llegamos así a las obras de madurez en que los textos referentes a los "vestigios trinitarios" se multiplican cada vez con mayor frecuencia. En todas ellas se insiste y precisan estos mismos conceptos. Especialmente al explicar los pasajes de los primeros capítulos del Génesis que hablan de la creación - tanto en la creación del mundo material, como en la creación especial del hombre-, o el capítulo primero del Evangelio de San Juan, Agustín alude invariablemente a la Trinidad y ve siempre insinuada la triple personalidad divina y su presencia en las cosas creadas.

Para el estudio de los diversos ternarios podemos elegir empezando por los más elevados o por los más bajos, pues ambos caminos ensayó el mismo Agustín. Pero es más oportuno -y mucho más frecuente también en Agustín- comenzar por las criaturas ínfimas para seguir ascendiendo hasta la sublimidad de Dios. En este sentido las tríadas corporales ejercen una magnífic labor propedeútica para el análisis y comprensión más sutil y difícil de las espirituales ${ }^{63}$. En tanto que las cosas tienen una independencia (ser o unidad) representan al Padre; en tanto que tienen una esencia peculiar (forma) representan al Hijo; en tanto que tienen una relación de totalidad (peso, orden) representan al Espíritu Santo. Ser, ser tal cosa, permanencia en el ser; unidad, forma, orden; medida, número, peso; modo, especie, orden... son huellas trinitarias y los bienes generales que el Dios creador, formador y conservador; omnipotente, sabio y amante; causa eficiente, ejemplar y final; Padre, Hijo y Espíritu han derramado en sus criaturas ${ }^{64}$.

\footnotetext{
"semejanza, como sinónima de "imagen". Los Padres griegos, especialmente Origenes, reservaban el término "semejanza" para el aspecto sobrenatural. Agustín corrige a Orígenes. Cf. Markus, ibid.

63. De Trin. XI, 1, 1; XII, 5, 5; XIV, 7, 9-10: PL 42, 984-5, 1001, 1043-4.

64. He aquí algunos textos más representativos: "Ut quemadmodum in ipso exordio inchoatae creaturae... commemorata est, Trinitas insinuatur creatoris, nam dicente Scriptura, In principio fecit Deus coelum et terram, intelligimus Patrem in Dei nomine, et Filium in Principii Nomine... Dicente autem Scriptura: Et Spiritus Dei ferebatur super aquas, completam commemorationem Trinitatis agnoscimus; ita et in conversione atque perfectione creaturae eadem Trinitas insinuatur" ( $D e$ Gen. ad Litt. I, 6, 12: PL 34, 250-1. Texto copiado en De Octo Dulcitii Quaest., q. 4, 2-3: PL 40, 167). "Cum ergo audimus, Et dixit Deus fiat, intelligimus quod in Verbo Dei erat ut fieret. Cum vero audimus: et sic factum est, intelligimus factam creaturam non excesisse praescriptos in Verbo Dei terminos generis sui. Cum vero audimus, Et vidit Deus quod bonum est, intelligimus in benignitate Spiritus eius non quasi cognitum posteaquam factum est placuisse, sed potius in ea bonitate placuisse ut manerer factum ubi placebat ut fieret" (Ibid. II, 6 14: PL 34, 268). "Ecce apparet mi-
} 
No vamos a analizar aquí todas las tríadas que Agustín investiga y enumera que, por lo demás, han sido ya recogidas por varios autores ${ }^{65}$. Baste con lo dicho. Pero sí es necesario notar dos observaciones principales. La primera, que la "analogía trinitatis" es el fundamento principal que determina y hace válida la semejanza entre Dios y la creación. Si queremos hablar del verdadero Dios cristiano sólo podemos hablar de El en cuanto es Trinidad. La estructura de la creación ha de ser similar a la de las procesio nes divinas ${ }^{66}$. Y sólo como "imitación" de la Trinidad las cosas son semejantes a Dios, pues así reflejan a su modo el rostro del Creador ${ }^{67}$.

La segunda, que la Trinidad es el modelo, la forma originaria de las criaturas. La unión o semejanza entre el Creador y la creación tiene a Dios como único fundamento y origen. No es lazo mutuo que hayan establecido de consuno Dios y las criaturas, sino que la ha establecido únicamente Dios, si bien afecta realmente

hi in aenigmate Trinitas... Et tenebam iam Patrem in Dei nomine, qui fecit haec, et Filium in principio nomine, in quo fecit haec, et Trinitatem credens Deum meum, sicut credebam, quaerebam in eoloquiis sanctis eius, et ecce Spiritus tuus superferebatur super aquas. Ecce trinitas, Deus meus, Pater et Filius et Spiritus Sanctus, creator universae creaturae" (Conf. XIII, 5, 6: PL 32 847; Cf. De Civ Dei. XI, 21-28: PL 41, 333-42). Especialmente aparece la Unidad y la Trinidad de Dios en la creación del hombre a su propia imagen: "Dixit Deus faciamus: ad insinuandam, scilicet, ut ita dicam, pluralitatem personarum propter Patrem et Filium et Spiritum Sanctum. Quam tamen deitatis unitatem intelligendam statim admonet, dicens: et fecit Deus hominem ad imaginem Dei..." (De Gen. ad Litt. III, 19,29ss: PL 34, 291-3; Conf. XIII, 22,32: PL 32, 858-9). "Haec itaque tria, modus, species et ordo, ut de innumerabilibus taceam quae ad ista tria pertinere monstrantur; haec ergo tria-modus, species et ordo- tanquam generalia bona sunt in rebus a Deo factis, sive in spiritu, sive in corpore" (De Natura boni 3: PL 42, 553). "Haec igitur omnia, quae arte divina facta sunt, et unitatem quamdam in se ostendunt, et speciem et ordinem. Quidquid enim bonum est, et unum aliquid est, sicut sunt naturae corporum, et ingenia animarum; et aliqua specie formatur, sicut sunt figurae vel qualitates corporum ac doctrinae vel artes animarum; et ordinem aliquam petit aut tenet, sicut sunt pondera vel collocationes corporum, atque amores aut delectationes animarum. Oportet igitur ut Creatorem, per ea quae facta sunt, intellectum conspicientes, Trinitatem intelligamus, cuius in creatura, quomodo dignum est, apparet vestigium. In illa Trinitate summa origo est rerum omnium, et perfectissima pulchritudo, et beatissima delectatio..." (De Trin. VI, 10, 12: PL 42, 932, etc.).

65. Cf. Portalie, Dict, The'ol. Cath. I, 2351-2; M. Schmaus, Die psychologische Trinitätslehre des hl. Augustinus (Münster 1927) 210-220; J. ITURRIOZ, "El trinitarismo en la filosofía de San Agustín": Revista Española de Teología 3 (1943) 118-126; L. ARIAS, Introducción al Tratado sobre la Santisima Trinidad (Madrid, BAC, 1958) 92-3.

66. Cf. nota 52 .

67. H. E. Henstenberg, Das Band, 147-158. 
sólo a las criaturas. La relación entre Dios y la criatura es personal y procedente de Dios. No se trata de una relación mutua, o como si Dios imitara - aunque fuera de modo eminente y sublimelas cualidades de las cosas. Como dice el mismo Agustín, es la imagen (o vestigio $=$ mundo) la que se coiguala al objeto, no el objeto a la imagen ${ }^{68}$. Pensamiento que se repite en multitud de ocasiones aplicándolo tanto al conocimiento como a la voluntad de Dios, según veremos ${ }^{69}$.

\section{a) Las huellas del Padre, como Origen.}

En primer lugar se manifiestan en el mundo las huellas del Padre. El Padre es el origen primero de todo ser; por tanto, la creación procede ante todo de $\mathrm{El}$, que a la vez que su origen es su última meta. Todas las criaturas deben llevar su impronta y la creación entera a El particularmente se atribuye, aunque como efecto "ad extra" tomen parte por igual las otras divinas Personas. En un sentido amplio podríamos decir que las primeras misiones del Hijo y del Espíritu Santo tienen lugar en la creación, en la que aparece la procesión trascendente de las criaturas y la existencia que por amor les otorga el Padre. La Palabra y el Amor del Padre resuenan en la nada dando origen a la variedad de los entes creados... Por eso las cosas manifiestan hacia el Padre una relación análoga semejante a la que une al Padre con el Hijo en el seno de la Trinidad. Esta es la función radical de la "palabra": dictar una orden o mandamiento, v. gr. "hágase la luz". Como el Padre habla su Palabra dentro de la Trinidad, así habla también su Palabra fuera de la Trinidad dando origen a la creación. Naturalmente con una abismal diferencia: la generación en el seno de la Trinidad se realiza en absoluta semejanza de naturaleza, mientras que en la creación se produce algo distinto de la divinidad ${ }^{70}$.

La propiedad personal del Padre es su carácter fontanal. Análogamente, en las tríadas creadas que Agustín señala, atribuye siempre al Padre lo originario y primordial. La presencia del Padre aparece, por ejemplo, en la materia informe, en el ser de las cosas, en la unidad y medida. Veamos brevemente qué entiende Agustín por "mensura".

68. De Trin. VI, 10, 11-12: PL 42, 932.

69. Cf. notas 83, 104 .

70. H. E. HenstenberG, Das Band., 159-160. 
Agustín toma este concepto de la vida corriente, refiriéndose a una medida de capacidad. Usamos determinadas "medidas" para medir el trigo, el oro o cualquier otra cosa. Después lo aplica a los planos superiores, es decir. al ser y unidad de cada cosa y a la potencia que tiene para conservarse en su cantidad o calidad ${ }^{71}$. El sentido del término "mensura" se aclara al examinar los estadios superiores y Agustín lo relaciona con las "razones seminales". Cada ente tiene una razón y medida de movimiento que impide un desarrollo desatinado y ciego, conservándose dentro de su propio "módulo" 72. Para los animales la mensura es ya orgánica y para los espíritus, espiritual. Entendemos mejor la mensura si consideramos el paralelo que Agustín establece entre la mensura y la "memoria" "2. Quiere decir que así como la memoria es en cierto modo la totalidad del contenido espiritual, la mensura resume todo el contenido potencial de los entes. La mensura se relaciona también con la unidad, que se convierte ahora en el primero de los ternarios, y aparece como origen y meta. Lo dicho anteriormente de la unidad, como huella del ser divino en general, cabe también aquí como huella peculiar del Padre. En efecto, la medida de los cuerpos y de los espíritus es relacionada con Dios, con el Padre, a quien llama Agustín "mensura quae omni rei modum praefixit" "4.

Por lo demás, Agustín entrecruza los planos ontológicos, psicológicos y morales. $Y$ desde la perspectiva de la unidad el pecado crea división, escisión del ser: "Mi impiedad me había dividido contra mí mismo" ${ }^{75}$. La iniquidad divide y la virtud unifica ${ }^{76}$.

b) Las huellas del Hijo, como Palabra.

El segundo momento de esta suerte de dialéctica de la creación - la formación- es el que corresponde a la segunda Persona

71. Epist. 102, 25: PL 33, 380.

72. De Gen. ad Litt. IV, 3, 7s.: PL 34, 299.

73. De Trin. XI, 11, 18: PL 42, 998.

74. De Gen. c. manich. I, 16, 26: PL 34, 185; De Gen. ad Litt. IV, 3, 7: PL 34, 299. Cf. E. MüLLER, Augustins Lehre, 21-3.

75. Conf. V, 10, 18: PL 32, 714. Agustín lo había experimentado en si mismo y lo describe con extraordinaria viveza cuando habla del periodo anterior a su conversión (cf. Ib. VIII, 5, 10-12, 30: PL 32, 753-764). Y había experimentado también que uno de los efectos más destacados de la conversión es justamente la unificación interior (Ib. IX, 1, 1, etc.: PL $32,763)$.

76. Conf. II, 1, 1; V, 10, 18; X, 20, 40; XII, 16, 23: PL 32, 675, 714, 796, 824. Cf. R. Florez, Las dos dimensiones, 169. 
de la Trinidad. Si el ser originario y primordial procede del Padre, el ser tal cosa se atribuye a la "Forma no formada", al Hijo. La creación es en este momento concebida metafóricamente como "respuesta" a la Palabra creadora de Dios. Agustín intenta explicarnos imaginativamente este segundo momento: Dios llama a la materia informe y en esta materia se da una especie de respuesta - conversión - a la llamada divina. Entonces Dios la ilumina dándole a cada cosa su propia forma o esencia. Lo cual es ejecutado por el Verbo, al modo de un sello estampado en la cera. Se trata de que cada cosa tenga su propio ser, con sus límites determinados, con su definición redondeada. He aquí, por otra parte, el modo concreto como se realiza el ejemplarismo ${ }^{7}$.

$Y$ porque las cosas realizan las ideas ejemplares del Verbo, por eso son semejanza de Dios. Como el Logos es la expresión verdadera de la sabiduría de Dios, así, análogamente, las cosas son expresiones - semejanzas- de la Mente divina, realizaciones concretas de las ideas subsistentes en el Logos en la unicidad de la divina esencia. A esta única palabra de Dios responde el coro de las cosas creadas, ecos temporales de la eterna Palabra. "Todo ha sido hecho por la Palabra". Podríamos burdamente imaginar que a través del Verbo - vuelto siempre hacia el Padre- suena la voz de Dios como la voz de alguien que llamara en el espacio a través de una ventana. El Verbo es como la ventana de la divinidad. El Verbo recibe su esencia del Padre y la da, expresándose, a las cosas que de algún modo le imiten ${ }^{78}$.

En el Verbo tenemos el modo como las cosas han sido hechas. "¿Cómo hiciste las cosas? No como un artífice de materia preexistente... Tú dijiste y fueron hechas, y con tu Palabra las hiciste. ¿Con qué palabra? No creada o sirviéndote de alguna criatura" ${ }^{79}$. La Palabra del Señor no está compuesta de sílabas que suenan en los espacios temporales. Es eterna, inmutable, inmensa. Es Dios como el Padre ${ }^{80}$. "En el Verbo hiciste las cosas, no como emanación de tu propia sustancia, sino "de la nada". El Verbo procede de ti, es tu misma sustancia; no así la criatura" ${ }^{81 . ~ E n ~ e l ~ H i j o ~ e s t a ́ n ~}$

77. Conf. XI-XIII, passim.; De Gen. ad Litt., passim. cf. A. EsPad, "Introducción": Estudio Agustiniano 3 (1968) 55-79.

78. H. E. HengstenBerg, Das Band, 161.

79. Conf. XI, 5, 7: PL 32, 811-812.

80. Conf. XI, 5, 7-7, 9: PL 32, 811-813

81. Conf. XII, 7, 7: PL 32, 828. 
las razones eternas de todo lo mudable; es el Principio, la Sabiduría - "Virtus et Sapientia"-, la Verdad, que ilumina y embellece, que convierte y amonesta ${ }^{82}$. La previa, eterna, inmutable Sabiduría de Dios es el principio de todas las criaturas ${ }^{83}$.

Señalemos como las huellas más destacadas de la segunda persona de la Trinidad la forma, la verdad, la hermosura, el número del mundo. Y así como el Hijo procede del Padre, la verdad y la hermosura brotan del ser y de la unidad ${ }^{84}$. La "forma" es la propiedad diferencial de los entes finitos, "qua discernitur"; es también el sello distintivo de la verdad y hermosura de los seres. Por la forma se imprime en ellos la semejanza con el ser supremo. El Verbo divino es la "Forma formarum", la "Forma non formata omnium formatorum" 85 .

Correlativamente a la "mensura", el ternario correspondiente al Verbo es el "numerus". Un concepto rico y complejo en la doctrina agustiniana ${ }^{86}$. El número es el que representa y precisa la esencia. Las cosas tienen forma, si el número la fija. Pues las cosas en tanto son tales, en cuanto se realizan en ellas tales números ${ }^{87}$. ¿No se opone esto al lema central de la metafísica agustiniana de que "nihil aliud est esse, quam unum esse"? ¿No dice Agustín que la multiplicidad menoscaba el ser? ¿Cómo puede poner junto a la unidad esos números, principios a su vez de ser? Aunque a primera vista parece que el concepto de número daña la unidad, Agustín se esfuerza por hacernos comprender que número y unidad se encuentran en la más estrecha relación ${ }^{88}$. Las cosas en tanto tienen número

82. De Gen. c. manich. I, 2, 3: PL 34, 174-175; Conf. XI, 8, 10ss; XII, 17, 25: 20, 29: 24, 33: PL 32, 813-814, 835, 836, 839; In Joan. Evang: 1, 5; 19,$3 ; 23$ 7: PL 35, 1381, 1544, 1586.

83. Dios conoce todos los seres antes de que éstos tengan realidad en el mundo: todos son previamente "vida" en el Verbo. Agustín lo repite infinidad de veces: "nosotros vemos las cosas porque existen; en cambio, ellas existen porque Tú las ves"... Conf. XIII, 38, 53: PL 32, 868; De Gen. ad Litt. II, 6, 14: V, 13, 29-19, 36: PL 34, 268, 331-334: Det Trin. VI, 10, 11: PL 42, 932; Ad Orosium contra Prisc. et Orig. 3, 3; 8, 9: PL 42, 671, 674; De Civ. Dei XI, 10 3; XI, 21:... PL 41, 327, 334...

84. E. GILsoN, Introduction, 280.

85. Ser. 117, 3: PL 38, 662.

86. P. M. VELEz, "El número agustiniano": Religión y Cultura 15 (1931, IV) 139-196; G. MARTIN, Klassische Ontologie der Zahl, Köln 1956; V. Tuesta, "Eficacia del número, según San Agustín": Estudio Agustiniano 3 (1968) 81-107; L. CIlleruelo, "Numerus et Sapientia": Ibid. 109-121. 87. De Lib. Arb. II, 16, 42: PL 32, 1263-1264.

88. Ibid. II, 8, 22: PL 32, 1252. 
en cuanto tienen unidad, ya que ésta es principio de aquel: los números se forman por agregación de unidades. Por eso, junto al principio de la unidad, pone Agustín el de complicatio o adiunctio. Agustín lo verifica en el número dos, formado por dos unidades. Los dos principios se dan juntos en el número tres, que de este mo do se hace número perfecto ${ }^{89}$. Si Agustín, como parece, pretende es tablecer paralelo con la divina Trinidad, podemos preguntarnos si no se realiza entonces en la segunda Persona una degeneración del Uno al modo de Plotino. Agustín quiere evitar ese peligro mostrando que los números son capaces de formar unidades superiores, presentando una "mística de los números" de marcada influencia pitagórica ${ }^{90}$. Las leyes de los números son eternas, inmutables, contenidas en la divina Sabiduría ${ }^{91}$. Representan un principio de formación y así son propiamente esenciales, permanentes y eternos dentro de los mismos entes; dan a las cosas el ser y la belleza. "Las leyes de la belleza se reducen a las leyes de los números" ${ }^{92}$. Estas leyes tienen especial aplicación al cuerpo humano, aunque los números espirituales son aun más perfectos ${ }^{93}$. Toda creación debe acomodarse a las leyes del número: el artista los contempla en sí mismo y los imprime en las obras que realiza; análogamente Dios creó el mundo por medio de los números ${ }^{54}$. Por aquí se ve que los cuerpos toman parte en la sabiduría de Dios por medio de los números ${ }^{95}$.

Algunas ideas anteriormente indicadas las mezcla Agustín con aplicaciones religiosas y morales. Si señalamos, por ejemplo, la "respuesta" como condición fundamental de este momento de la creación, comprendemos que se trata ante todo de una "respuesta ontológica", común a todos los seres. Pero en Agustín lo ontológico no está separado de lo antropológico, psicológico, moral, religioso. La respuesta consciente de la criatura capaz de ella constituye un aspecto fundamental del acto religioso en el sentido más propio. $\mathrm{Y}$ si nos dejamos ya conducir por la revelación cristiana, ve-

89. De Mus. I, 12, 21: PL 32, 1095.

90. Det Gen. ad Litt. IV, 2, 2ss: PL 34, 296-302.

91. De Lib. Arb. II, 11, 31: PL 32, 1258.

92. De Lib. Arb. II, 16, 42: PL 32, 1263-1264; De Trin. XII, 14, 23: PI,

42, 1010; De Civ. Dei XXII, 24, 4: PL 41, 791.

93. De Mus. VI, 11, 29-33: PL 32, 1179-1181.

94. De Lib. Arb. II, 11, 30: PL 32, 1257.

9,5. Ibid. II, 11, 31: PL 32, 1258. Cf. E. MÜLLER, Augustins Lehre, 2426 ; L. Cilleruelo, art. cit. 
mos cómo la última y más perfecta respuesta a Dios la ha dado Cristo, el Si constante del Padre. $Y$ en Cristo todo cristiano puede realizar el bello sueño de llamar también a Dios "Padre". Esta superior forma de respuesta, esta participación de la vida trinitaria por Cristo en el Espíritu - que constituye la esencia del misterio sobrenatural de la gracia- se puede realizar porque previamente tenemos ese sólido fundamento en los estadios inferiores ${ }^{96}$. Inversanmente, el pecado aleja de Dios, nos sitúa en la región de la desemejanza ${ }^{97}$. Es aversión, vuelta a la tiniebla. Deja de ser uno mismo al abandonar a Dios, arrojándose fuera de sí. El pecado des-esencia, des-naturaliza... ${ }^{88}$.

c) Las huellas del Espíritu, como Amor.

El Espiritu Santo es en la Trinidad el lazo de amor que une al Padre y al Hijo, el relativo final y el término último que cierra el cielo de las procesiones divinas. El es también el lazo de unión entre Dios y las criaturas. El Padre crea por la palabra (da la orden), el Hijo es principio formal y ejemplar, el Espíritu Santo ejecuta, realiza lo ordenado por el Padre. El mundo es término del Amor divino. Por eso corresponde al Espíritu Santo lo que signifique ejecución y puesta en la existencia de las criaturas e igualmente el impulsar el mundo entero en todo su devenir ${ }^{99}$. Impulso realizado no simplemente "desde fuera", como si la trascendencia divina anulara la inmanencia; no con frías órdenes dictatoriales, sino que sus leyes son expresiones de un lazo delicado de amor por el que Dios se une a la criatura. El amor de Dios está presente en cada caso que se da creatividad. Cada impulso de la creación al ser se fundamenta necesariamente en un amor preexistente, eterno, gratuito del Creador. Toda realización creada expresa un amor "ad extra"

96. H. E. Hengstenberg, Das Band, 165-166.

97. Los conceptos de semejanza y desemejanza, cercanía y lejanía. -tomados nuevamente de Plotino- adquieren en Agustín un esencial enriquecimiento, y le sirven para expresar con gran fuerza profundas vivencias religiosas. Véase, por ejemplo, el texto siguiente: "Quid est illud quod interlucet mihi, et percutit cor meum sine laesione; et inhorresco, et inardesco? Inhorresco in quantum dissimilis ei sum; inardesco in quantum similis ei sum. Sapientia ipsa est, quae interlucet mihi... Conf. $\mathrm{XI}, 9,11$ : PL 32, 813. Cf. B. BRAvo, Angustia y gozo en el hombre. Aportaciones al estudio de la antropología agustiniana (Madrid 1957).

98. R. FLOREz, Las dos dimensiones, 79-89, etc.

99. De Gen. ad Litt. I, 8, 14: PL 34, 251; Conf. XIII, 2, 2; 4, 5; 8, 9; 33, 48: PL 32, 846-848, 866, etc. 
en la misma creación. Porque Dios coloca a la criatura bajo la mirada del amor, se da la creación ${ }^{100}$.

"Spiritus Domini replevit orbem terrarum". El adelantarse de Dios frente a la creación es un envolverla en el amor. La creación no sería "arrojada" a la realidad si no la recibiera del inmenso amor de Dios. El amor de Dios, que es idéntico a su esencialidad - "Dios es Amor"-, no conoce el paso de lo potencial a lo actual. Está siempre activo. Por eso, el amor de Dios no se inflama al ver la obra realizada (como el artista se entusiasma al contemplar terminada su obra de arte), sino al revés: la realidad de la creación palpita por el amor previo de Dios: "amor Dei est creans et infundens bonitatem in rebus", dirá después Santo Tomás siguiendo a San Agustín ${ }^{101}$.

Al Espíritu Santo se apropian las obras de amor, tanto en el orden de la naturaleza como en el de la gracia. En primer lugar, El es el lazo entre Dios y el mundo en el orden natural. El coloca a cada individuo dentro del conjunto total ordenado de la creación. Todas las cosas forman una determinada comunidad natural. Cada ente finito es lo que es solamente porque muchos otros son con él, de esta manera determinada, aquí y ahora. Es la ontología relacional. Todo lo finito está desde el origen en reciproca relación según el estatuto ontológico —el peso- de cada ser. Cada ente está en comunidad con otros entes, según su propio peso. Cada cosa del mundo no tiene una existencia aislada, sino que están todas integradas dentro de una totalidad, que a su vez se ordena a planos superiores. Así tenemos que los entes irracionales se ordenan al hombre, el hombre individual tiene que realizar su existencia dentro de la historia universal y la historia humana está ordenada al misterio de Cristo y de la Iglesia y convertida en historia de salvación. También esta labor dentro del mundo de la gracia es propia del Espíritu Santo ${ }^{102}$.

100. Conf. XII, 7, 7; XIII, passim: PL 32, 828, 846ss, etc. Cf. H. E. HengSTENBERG, Das Band, 17-18.

101. Summa Theol, I, q. 20, 2; I, q. 23, 4; I-II, q. 110, 1; III, q. 86, 2, etc. Para San Agustín, cf. notas 83 y 104.

102. Conf. XIII, passim: PL 32, 845ss. Cf. H. E. Hengstenberg, Das Band, 17-18. En el tema del amor Agustín es deudor de las especulaciones platónicas y de las enseñanzas bíblicas. Pero aquí de un modo especial ha sido capaz de expresar sus propias vivencias y ha logrado aciertos decisivos. Se comprende que autores modernos (Scheler, Marcel etc.) 
Con ello queda establecido el lazo entre Dios y su creación por la presencia y acción del Espíritu en las criaturas: Dios crea por amor. El Espíritu Santo, que es el lazo de amor en el seno de la Trinidad es también quien establece con las criaturas el lazo de su propiedad personal ${ }^{103}$. Mas cuando decimos que el Espíritu es el lazo entre Dios y la creación, tenemos nuevamente que hacer las salvedades acostumbradas, es decir, que el Espíritu Santo es el lazo "ad extra" de muy distinto modo a como lo es en el seno de la Trinidad. En Dios toda su personalidad la recibe de la procedencia del Padre y del Hijo; en cambio si se trata de la creación su personalidad no depende para nada de las criaturas. Al contrario, el fundamento o principio de unión está únicamente del lado de Dios y no de éstas. Dios mantiene las cosas en unión y solamente por ella subsisten. El lazo lo establece Dios y no la criatura; es previo y fundante ${ }^{104}$.

Se comprende, pues, que la creación procede de la libérrima voluntad de Dios. No es ya una emanación o difusión necesaria, sino libre ${ }^{105}$. La creación es también "Gracia": subsiste esencialmente en el amor, que es don gratuito. Las cosas existen en la medida en que son productos del amor: concebidas por el amor y capaces de responder al amor. En el cristianismo y en el pensamiento de Agustín "todo es gracia" ${ }^{106}$. Finalmente, las cosas que proce-

acudan con frecuencia a San Agustín para explotar sus intuiciones maravillosas. Cf. S. Agostino e le grandi correnti della filosofia contemporanea. Atti del Congresso italiano di filosofia agostiniana (Roma 1954).

103. H. E. HengstenBERG, Das Band, 168-169.

104. La voluntad de Dios no es creación alguna, sino anterior a toda creación. Su bondad lo ha precedido y causado todo. Todo es don gratuito de su amor... Conf. XI 10, 12 ; XIII, 1, 1-4, 5, etc.: PL 32, 814, 845ss. Cf. nota 83 .

105. Conf. XIII, passim: PL 32, 845ss.; De Gen ad Litt. I, 5, 11: PL 34, 250, etc. La contraposición entre el pensamiento bíblico (Dios creo porque quiso) y el helénico (el mundo es emanación necesaria de la bondad divina) es solucionada por Agustín al afirmar que el "Primer Amor" es también la "Primera Libertad". Por eso, también aquí cabe aplicar su frase: "La ley del amor no es ley de necesidad, sino de libertad" (Epist. 167, 6, 19: PL 33, 740. Cf. R. N. CosineaU, "Creation and Freedom. An angustinian Problem: "Quia voluit" or "Quia bonus est?": Recherches Augustiniennes II (Paris 1962) 253-271..

106. El libro XIII de Confesiones es especialmente explícito a este respecto.: únicamente al amor libérrimo de Dios se debe el que las cosas existan. "De la plenitud de tu bondad subsiste la criatura, etc.". La gracia de Dios, que Agustín ha experimentado en sí mismo, la aplica a todos los seres (Cf. A. Holl, Die Welt der Zeichen bei Augustin (Wien 1963) 92ss. 
den de la bondad divina, son ellas también buenas: cada una buena y en conjunto muy buenas ${ }^{107}$.

Las huellas del Espíritu en las criaturas se manifiestan en las dimensiones relacionadas con el amor: en la existencia concreta de los seres, en la bondad y peso de cada uno y en orden del conjunto cósmico. Todos estos conceptos tienen gran importancia en la doctrina de Agustín, aunque no siempre podamos comprobar como deseamos los contornos precisos de cada uno ${ }^{108}$.

Orden es la regla con que Dios dirige todas las $\operatorname{cosas}^{109}$ y en este sentido se relaciona con la ley eterna ${ }^{110}$. Procede de Dios $^{111}$ y se aplica tanto a cada ente en particular, como a la universalidad de todos ellos ${ }^{112}$. Como el Espíritu procede del Padre y del Hijo, el orden se relaciona con la unidad y la idea. Procede primero de la unidad, según indicamos anteriormente. El orden procede también de la idea: las cosas han sido creadas a través del Verbo como proyectos; por eso existe un "ordo rerum". "Las cosas ordenadas entre sí están además ordenadas en sí mismas y el orden viene a ser así uno de los trascendentales" ${ }^{113}$. Hay una ley natural que es la impresión en el mundo, y particularmente en el hombre, de la ley eterna. Esta ley eterna se define como "razón o voluntad de Dios que manda conservar el orden natural y prohibe perturbarlo". Y realiza su función específica y fundamental logran-

107. Agustín lo afirma en infinidad de textos. Véase por ejemplo, el mismo libro XIII de las Confesiones. Dios bueno no pudo crear sino cosas buenas; la bondad divina se refleja aun en los seres más diminutos: "Deus ita est artifex magnus (maximus) in magnis, ut minor non sit in parvis" (De Civ. Dei XI, 22: PL 41, 335).

108. En varios pasajes, pero especialmente en el mismo libro XIII de Confesiones, es básico el concepto de "peso". El peso "ontológico", que coloca a cada ser en el orden cósmico, y el peso "psicológico" del hombre, que es su amor. Según los diversos pasos se establece en el universo la "jerarquía de los seres"... Agustín suscribiria gustoso estas palabras de Zubiri: "El peso o el amor no es algo que afecte accidentalmente a las criaturas, o una simple virtud de la voluntad, sino la más profunda dimensión metafísica de la realidad" (Naturaleza, Historia, Dios (Madrid 1944) 479). Para comprobar el pensamiento de San Agustín, véase, entre otros, los textos siguientes: Conf. XIII, 9, 10: PL 32, 848; Epist. 55, 10, 18, 157, 2, 9: PL 33, 212-213, 677; In Ps. 9, 8: PL 36, 124; De Civ. Dei XI, 28: PL 41,342 , etc.

109. De Ord. II, 7, 21: PL 32, 1004

110. De Civ. Dei XIX, 14: PL 41, 728.

111. De Ord. 1, 7, 17: PL 32, 986.

112. Ibid. I, 1, 1: PL 32, 977-979.

113. R. FLoREz, Presencia, 172. Cf. J. RIEF, Der Ordobegriff des jungen Augustinus (Paderborn 1962). 
do el mantenimiento del "ordo", haciendo ut "omnia sint ordinatissima" ${ }^{114}$,

Las múltiples representaciones del orden que nos ofrece Agustín denuncian la plasticidad de la noción. Más que el orden en su aspecto estático, nos interesa estudiarlo en su aspecto dinámico, es decir, en cuanto que el orden del mundo es para Agustín como un trampolín del hombre en su búsqueda de Dios ${ }^{115}$. Agustín mismo confiesa que frecuentemente él se eleva a Dios al comtemplar el orden creado: "saepe istud facio" ${ }^{116}$. Pero el orden de que aquí se trata no es inmanente, como en Plotino ${ }^{117}$, sino que Agustín al romper con esa procesión emanativa de Plotino no puede admitir tampoco su inmanencia absoluta ${ }^{118}$.

Con el orden está conexa la noción tan socorrida por Agustín de peso, que él aplica tanto a los cuerpos como a los espíritus. El peso es ordenador porque impulsa cada cosa a su centro. "Pondus" es el impulso que coloca a los cuerpos en su lugar debido y de ese modo ordena el mundo ${ }^{119}$. El pondus es como el elemento voluntarista de los seres, en que insistía Schopenhauer. Agustín ve en el pondus el ímpetu hacia el orden establecido por Dios, hacia la armonía pacífica universal. Así establece un paralelo entre las criaturas superiores y las inferiores ${ }^{120}$. Las cosas ordenadas logran quietud y cuando hay desorden viene la inquietud 121. La paz, la quietud que toda criatura ordenada respira es un "donum Spiritus Santi". Por tanto, el Espíritu Santo trabaja e influye como una especie de imán gigantesco al que tienden todas las cosas. El es la razón de todo desarrollo y de todo movimiento ${ }^{122}$. $\mathrm{Y}$ el amor, el orden y el peso conducen de nuevo a la unidad, a aquella unidad terminal de que hablamos anteriormente ${ }^{123}$.

114. De Lib. Arb. I, 6, 15: PL 32, 1229. R. FloREZ, Presencia, 173-175.

115. G. MADEC, en Revue des Etudes Augustiniennes, 9 (1963) 139-146.

116. Conf. X, 40, 65: PL 32, 807.

117. Enn. V, 4, 10.

118. G. MADEC, ibid.

119. "Est impetus cuiusque rei velut conantis ad locum suum: hoc est pondus..." (In PS. 29, 2, 10: PL 36, 222s).

120. Conf. I, 1, 1: PL 32, 661; De Civ. Dei XI, 28: PL 41, 341-342; In Ps. 29, 2, 10: PL 36, 222-223.

121. Quietud y paz están, pues, en relación con el "pondus" y el "ordo" (Conf. XIII, 8, 9s: PL 32, 848-849; De Civ. Dei XIX, 13: PL 41, 640).

122. Conf XIII, 9, 10: PL 32, 848-849, etc.

123. Ese elemento ordenador pertenece a la unidad y la unidad armónica es lo que busca toda criatura (De Civ. Dei XIX, 12ss: PL 41, 637643). 
Se comprende cómo de nuevo nos encontramos - por diversos caminos - en el circulo de la trinidad y de la unidad mutuamente implicadas; que se da, en definitiva, una especie de "perijóresis". En la mensura tenemos la unidad en reposo, cerrada en sí misma, de los cuerpos; en el numerus, la formación armónica y bella que lleva a cada cosa a expresar su medida-capacidad; en el pondus, la tendencia a la unidad terminal y al orden armónico dentro de la ley natural y divina, dentro de la paz y la unidad del cosmo. Los tres miembros del ternario se refieren a una misma cosa y juntos contribuyen al fin de la "formación epara la unidad" y la "unidad de todo el mundo" ${ }^{124}$.

El amor divino originario del cual brotaron las criaturas es también el término definitivo al que todas tienden, encontrando su descanso en este amor trascendente y envolvente. "Vista desde Dios la creación es una efusión de amor; vista desde la criatura la efusión del amor es una atracción ascensional hacia Dios" ${ }^{125}$. "En tu Don descansamos: alli te gozamos. Nuestro descanso es nuestro lugar" 126.

Agustín entremezcla de nuevo las aplicaciones morales. La caridad que el Espíritu difunde nos eleva; el amor a las cosas infimas nos relaja ${ }^{127}$. Porque la misión de las cosas consiste en ser perpetua invitación y reclamo del amor al Creador ${ }^{128}$.

\section{Conclusión: el sentido del Mundo.}

Si las investigaciones de Agustín han contribuido decisivamente a establecer el misterio del Dios Trinidad, con mayor razón tenemos que decir que sus especulaciones trinitarias han contribuido al progreso de la psicología y también a una comprensión reli-

124. E. MÜLLER, Augustins Lehre, 28-29.

125. X. ZuBIRI, Naturaleza, 512.

126. Conf. XIII, 9, 10; 35, 50ss: PL 32, 848-849, 866-868; De Gen. ad Litt. V, 21, 42ss.: PL 34, 336-338.

127. "Omnis amor aut ascendit, aut descendit. Desiderio enim bono levatur ad Deum, et desiderio malo ad ima pracipitamur" (In Ps. 122, 1: PL 37, 1629-1630). "Amando Deum efficimur dii; amando mundum, dicimur mundus" (Ser. 121, 1: PL 38, 678). Conf. XIII, 7, 8SS: PL 32, 846848; In Epist. Joan II, 14: PL 35, 1997; In Ps. 83, 9; 121, 1: PL 37, 1063, 1618; De Civ. Dei XIV, 28: PL 41, 436, etc.).

128. Conf. VIII, 1, 2; X, 6, 8s: PL 32, 749, 782-783; In Ps. 39, 8; 145, $5 ; 12-31$ : PL 36,$439 ; 37,1887,1892-1893$, etc. 
giosa del mundo ${ }^{129}$. Agustín contempla con ojos optimistas el universo corporal y espiritual, como obra de Dios que es en la que ha dejado impresa su huella trinitaria. Dios es causa eficiente, ejemplar y final. En textos luminosos de sabor platónico resume su con cepto del Dios Trino y Creador: "Deus est causa subsistendi, et ratio intelligendi, et ordo vivendi" 131; "Deus est causa constitutae universitas, et lux percipiendi veritatis, et fons bibendae felicitatis" ${ }^{131}$.

Aunque se noten con frecuencia en Agustín reminiscencias platónicas, el concepto de creación, al que de una manera implícita o explícita nos tenemos que referir constantemente, ha cambiado de modo radical la mentalidad antigua. Si el mundo refleja la unidad, la verdad y la bondad de Dios; si ha sido creado conforme a las ideas divinas, tiene que estar cargado de sentido y la totalidad de su ser no se agota en la experiencia inmediata y tangible. El mundo entero es contemplado a la luz de Dios, con los ojos de Dios, como reflejo de su ser, de su hermosura y de su bondad. Es cierto que para que las cosas digan algo - mejor dicho, para que su voz pueda ser atendida y entendida- es preciso tener limpios los ojos del espíritu; pero ahí están con la elocuente voz de su presencia ${ }^{132}$.

El mundo es siempre para el creyente una epifanía de Dios. Dios ha pasado y en él ha derramado sus bondades; ha impreso sus huellas divinas que sirven al hombre peregrino de sendero para llegar al Creador. Conocido el Creador, volvemos nuestra mirada hacia el mundo que aparece en una nueva luz. Parecido a como si nosotros, siguiendo una huella oscura llegamos a una cima y desde alli echamos una mirada al campo recorrido, sobre el cual el camino antes borroso queda ahora claro. Cada uno de los pasos dados anteriormente con vacilación, después que hemos conseguido la meta, se nos presenta como algo completamente nuevo. De modo parecido sucede con nuestra visión del mundo, después que hemos llegado a un conocimiento de Dios. Este mismo conocimiento nos ayudará a completar y redondear nuestra vi-

129. Cf. Schmaus, Die psychologische, 417; E. MüLLER, Augustins Lehre, 48-49.

130. De Civ. Dei VIII, 4: PL 41, 228.

131. De Civ. Dei VIII, 10, 2: PL 41, 235. Cf. F. J. Thonnard, "Caractères platoniciennes de l'ontologie augustinienne": Augustinus Magister I (Paris 1955) 317-327.

132. Conf. X, 6, 8ss: PL 32, 782ss. 
sión del cosmos. No hay ningún detalle del mundo que no deba ser repensado en nueva luz, en una luz superior. Hemos avanzado primero desde la tierra, de abajo hacia arriba. Ahora nuestra mirada es desde arriba hacia abajo y los escalones del camino quedan nuevamente iluminados ${ }^{193}$.

De modo similar a como el hombre es un misterio sublime que sólo puede ser iluminado desde el ángulo de lo divino así late también en el mundo una misteriosa realidad que le trasciende. El ser revelado en la creación sobrepasa infinitamente el ser concreto entendido en su materialidad. En el ser del hombre y de las cosas late una inmensa riqueza de sentido que nos remite más allá del hombre y del universo ${ }^{134}$. Este sentido está en comprender la presencia en él -inmanente y trascendente- del Creador. Es la alabanza al Creador en y por la creación. Es el retorno de todos los seres a su origen primero. "El nos ha hecho" claman todos ellos con potente voz. Cuando esto se comprende, "lo que aparece en primer término es la apelación a las cosas como signo... Estamos en el momento de la nueva conquista del mundo: un mundo transfigurado y bendecido, en el que está patente todo lo que tiene de cita, de augurio, de remando de eternidad" ${ }^{135}$. Las cosas se convierten en "cifras", o en "vestigios, "signos", "anuncios", reflejos", "admoniciones" ... que estas y otras palabras emplea el mismo Agustín.

Y por las cosas se establece la "ascensión gradual" de que hablamos al principio. Las criaturas cantan la gloria de Dios. Por las cosas visibles hemos de subir al Creador invisible. Agustín tieen textos elocuentes que podemos multiplicar cuando queramos. He aquí algunos: "Tu creación fue un espectaculo para mi. Busqué en la obra del artífice y en todas las cosas creadas al Creador" ${ }^{136}$. "Non amemus creaturam neglecto creatore, sed attendamus creaturam et laudemus Creatorem... Facta inspice, lauda factorem" ${ }^{137}$. "Ne sis ingratus ei qui te fecit videre, unde possis credere quod nondum potest videre. Dedit tibi Deus oculos in corpore, rationem

133. H. E. Hengstenberg, Das Band, 11-13.

134. Conf. IV, 4, 9s.; X, 8, 14-14, 22; 16,$25 ;$ XIII, 31, 46...: PL 32, 697, 785-790, 865; In Ps. 39, 8: PL 36-439.

135. R. FloREz, Presencia, 85-89.

136. In Ps. 142, 10: PL 37, 1851.

137. Ser. 261, 4, 4: PL 38, 1204. 
in corde. Crede in eum quem non vides, propter ista quae vides" ${ }^{138}$. "Dé vueltas tu ánimo por la creación entera; por todas partes te gritará: Dios me hizo. Todo lo que te deleita en el arte avalora al artífice. ¿Ves los cielos? Son obras maravillosas de Dios. ¿Ves la tierra? Dios estableció las virtualidades de las semillas, las especies de las plantas y la multitud de los animales. Da vueltas todavía por los cielos hasta llegar a la tierra, nada dejes de observar, por todas partes te gritan aclamando al Creador de todas las cosas; las mismas bellezas de las criaturas son voces que alaban al Creador" ${ }^{139}$. "En verdad que, si piadosa y atentamente lo consideras, verás que la belleza y el movimiento de las criaturas, que pueden ser objeto de nuestra consideración, son para nosotros una gran lección, porque mediante sus diversos movimientos y modificaciones, como mediante otras tantas lenguas, nos llaman e invitan clamorosamente al conocimiento del Creador" ${ }^{140}$.

La función del mundo es trasmitirnos un mensaje, decirnos una palabra: la palabra de las cosas consiste en ser espejo y eco de la palabra de Dios.

\section{A. Espada.}

138. Ser. 126, 2, 3: PL 38, 699 .

139. In Ps. 26, II, 12: PL 36, 205. Cf. In PS. 144, 13-15: PL $371877-$ 1879 ; nota 128.

140. De Lib. Arb. III, 23, 70: PL 32, 1305. 